\title{
Occupancy of wild southern pig-tailed macaques in intact and degraded forests in Peninsular Malaysia
}

\author{
Anna Holzner ${ }^{1,2,3}$, D. Mark Rayan ${ }^{4,5}$, Jonathan Moore ${ }^{6,7}$, Cedric Kai Wei Tan ${ }^{8,9}$, Laura Clart ${ }^{2}$, Lars Kulik ${ }^{1}$, Hjalmar \\ Kühl ${ }^{10}$, Nadine Ruppert ${ }^{\text {Corresp., } 3}$, Anja Widdig ${ }^{1,2,10}$ \\ 1 Department of Human Behaviour, Ecology and Culture, Max Planck Institute for Evolutionary Anthropology, Leipzig, Germany \\ 2 Behavioural Ecology Research Group, Institute of Biology, University of Leipzig, Leipzig, Germany \\ 3 School of Biological Sciences, Universiti Sains Malaysia, Pulau Pinang, Malaysia \\ 4 Durrell Institute of Conservation and Ecology (DICE), University of Kent, Canterbury, United Kingdom \\ 5 Wildlife Conservation Society (WCS) Malaysia Program, Petaling Jaya, Malaysia \\ 6 School of Environmental Science and Engineering, Southern University of Science and Technology, Shenzhen, China \\ 7 School of Environmental Sciences, University of East Anglia, Norwich, United Kingdom \\ 8 Wildlife Conservation Research Unit, Department of Zoology, University of Oxford, Oxford, United Kingdom \\ 9 School of Environmental and Geographical Sciences, University of Nottingham Malaysia, Semenyih, Malaysia \\ 10 German Center for Integrative Biodiversity Research, Leipzig, Germany \\ Corresponding Author: Nadine Ruppert \\ Email address: n.ruppert@usm.my
}

Deforestation is a major threat to terrestrial tropical ecosystems, particularly in Southeast Asia where human activities have dramatic consequences for the survival of many species. However, responses of species to anthropogenic impact are highly variable. In order to establish effective conservation strategies, it is critical to determine a species' ability to persist in degraded habitats. Here, we used camera trapping data to provide the first insights into the temporal and spatial distribution of southern pig-tailed macaques (Macaca nemestrina, listed as 'Vulnerable' by the IUCN) across intact and degraded forest habitats in Peninsular Malaysia, with a particular focus on the effects of clear-cutting and selective logging on macaque occupancy. Specifically, we found a $10 \%$ decline in macaque site occupancy in the highly degraded Pasoh Forest Reserve from 2013 to 2017. This may be strongly linked to the macaques' sensitivity to intensive disturbance through clear-cutting, which significantly increased the probability that $M$. nemestrina became locally extinct at a previously occupied site. However, we found no clear relationship between moderate disturbance, i.e. selective logging, and the macaques' local extinction probability or site occupancy in the Pasoh Forest Reserve and Belum-Temengor Forest Complex. Further, an identical age and sex structure of macaques in selectively logged and completely undisturbed habitat types within the Belum-Temengor Forest Complex indicated that the macaques did not show increased mortality or declining birth rates when exposed to selective logging. Overall, this suggests that low to moderately disturbed forests may still Peer] reviewing PDF | (2021:04:59765:1:1:NEW 26 Sep 2021) 
constitute valuable habitats that support viable populations of $M$. nemestrina, and thus need to be protected against further degradation. Our results emphasize the significance of population monitoring through camera trapping for understanding the ability of threatened species to cope with anthropogenic disturbance. This can inform species management plans and facilitate the development of effective conservation measures to protect biodiversity. 
1 Occupancy of wild southern pig-tailed macaques in intact

2

3

4

6

7

\section{and degraded forests in Peninsular Malaysia}

Anna Holzner 1,2,3, D. Mark Rayan,5, Jonathan Moore ${ }^{6,7}$, Cedric Kai Wei Tan ${ }^{8,9}$, Laura Clart², Lars Kulik ${ }^{1}$, Hjalmar Kühl ${ }^{10}$, Nadine Ruppert ${ }^{3 *}$, Anja Widdig ${ }^{1,2,10}$

${ }^{1}$ Department of Human Behaviour, Ecology and Culture, Max Planck Institute for Evolutionary Anthropology, Leipzig, Germany

2 Behavioural Ecology Research Group, Institute of Biology, University of Leipzig, Leipzig, Germany

${ }^{3}$ School of Biological Sciences, Universiti Sains Malaysia, Pulau Pinang, Malaysia

${ }^{4}$ Wildlife Conservation Society (WCS) Malaysia Program, Petaling Jaya, Malaysia

${ }^{5}$ Durrell Institute of Conservation and Ecology (DICE), University of Kent, Canterbury, United Kingdom

${ }^{6}$ School of Environmental Science and Engineering, Southern University of Science and Technology, Shenzhen, China

${ }^{7}$ School of Environmental Sciences, University of East Anglia, Norwich, United Kingdom

${ }^{8}$ Wildlife Conservation Research Unit, Department of Zoology, University of Oxford, Oxford, United Kingdom

${ }^{9}$ School of Environmental and Geographical Sciences, University of Nottingham Malaysia, Semenyih, Malaysia

${ }^{10}$ German Center for Integrative Biodiversity Research, Leipzig, Germany

*Corresponding author:

Nadine Ruppert

Email address: n.ruppert@usm.my 


\section{Abstract}

Deforestation is a major threat to terrestrial tropical ecosystems, particularly in Southeast Asia where human activities have dramatic consequences for the survival of many species. However, responses of species to anthropogenic impact are highly variable. In order to establish effective conservation strategies, it is critical to determine a species' ability to persist in degraded habitats. Here, we used camera trapping data to provide the first insights into the temporal and spatial distribution of southern pig-tailed macaques (Macaca nemestrina, listed as 'Vulnerable' by the IUCN) across intact and degraded forest habitats in Peninsular Malaysia, with a particular focus on the effects of clear-cutting and selective logging on macaque occupancy. Specifically, we found a 10\% decline in macaque site occupancy in the highly degraded Pasoh Forest Reserve from 2013 to 2017 . This may be strongly linked to the macaques' sensitivity to intensive disturbance through clear-cutting, which significantly increased the probability that $M$. nemestrina became locally extinct at a previously occupied site. However, we found no clear relationship between moderate disturbance, i.e. selective logging, and the macaques' local extinction probability or site occupancy in the Pasoh Forest Reserve and Belum-Temengor Forest Complex. Further, an identical age and sex structure of macaques in selectively logged and completely undisturbed habitat types within the Belum-Temengor Forest Complex indicated that the macaques did not show increased mortality or declining birth rates when exposed to selective logging. Overall, this suggests that low to moderately disturbed forests may still constitute valuable habitats that support viable populations of $M$. nemestrina, and thus need to be protected against further degradation. Our results emphasize the significance of population monitoring through camera trapping for understanding the ability of threatened species to cope with anthropogenic disturbance. This can inform species management plans and facilitate the development of effective conservation measures to protect biodiversity.

\section{Introduction}

4 Tropical rainforests are highly complex ecosystems that exhibit exceptional biodiversity (Gallery, 2014). Yet, continuing human population growth, expanding infrastructure and the intensive cultivation of crops lead to dramatically increasing deforestation rates, which are the major threat to these remarkable habitats (Rosa et al., 2016). Southeast Asia, for example, one of 
58 the world's most biodiverse regions and home to many charismatic primate species (Myers et al. 59 2000; Sodhi et al. 2010), has lost about 80 million hectares of forest between 2005 and 2015

60 (Estoque et al. 2019).

61 It is well known that human land use drastically reduces biodiversity and important ecosystem 62 functions of primary forests (Marques et al., 2019; Alroy, 2017; Barnes et al., 2014). Degraded habitats, such as forest fragments, monocultures or urban environments, were shown to include on average $41 \%$ fewer species than undisturbed forests (Alroy, 2017). Numerous studies have highlighted the negative impact of forest clear-cutting on biodiversity, with the conversion of tropical forests into oil palm plantations being the main driver of deforestation in many Southeast Asian countries (Koh \& Wilcove, 2007; Fitzherbert et al., 2008). The establishment of oil palm monocultures does not only imply severe losses in species richness but also substantially contributes to habitat fragmentation and environmental pollution through chemical fertilizers or pesticide runoffs (reviewed in Fitzherbert et al., 2008). Particularly, larger mammals and specialized bird species that have a narrow dietary spectrum may have difficulties in permanently adapting to and surviving in these monocultural landscapes (Danielsen \& Heegaard, 1995; Fitzherbert et al., 2008). The negative effects of habitat degradation on animal populations may further be reinforced by the increase of so-called 'edge effects', describing ecological alterations that result from the development of abrupt, artificial edges of forest fragments (Didham et al., 1998). Forest edges open the canopy and dry out the wood, which increases the susceptibility of forests to fire (Cochrane, 2003).

Selective logging is one of the most widespread, albeit less intensive, forms of habitat degradation (Asner et al., 2005). It refers to the removal of a limited number of economically valuable tree species of a given age in a particular area and/or during a distinct logging cycle (Johns, 1985). However, it also implies secondary threats, such as an increased hunting pressure from local communities, as logging roads facilitate human access to forests (Robinson, Redford \& Bennett, 1999; Milner-Gulland \& Bennett, 2003). Previous research suggested that selective timber extraction may have less severe effects on species diversity and abundance than more intensive forms of land use change, e.g., through clear-cutting (Ibarra et al., 2017; Gibson et al., 2011). However, Tobias (2015) highlighted the high variability in the reaction of different species to habitat degradation, with both logging practices as well as species traits, such as diet and body mass, being important factors in determining the effects of selective timber harvesting 
89

90

91

92

93

94

95

on wildlife abundance. This is in line with other studies suggesting that generalist feeding tendencies in particular are indicative of the ability of a species to persist in selectively logged habitats(Vetter et al., 2011; Burivalova et al., 2015). Indeed, some species were found to have a higher abundance in moderately disturbed compared to primary forest habitats, including several ungulates (Brodie, Giordano \& Ambu, 2015), rodents, and granivorous bird species (Bicknell \& Peres, 2010). Carnivores, as well as frugivorous forest specialists, on the other hand, were often reported to be confined to undisturbed primary forests (Brodie, Giordano \& Ambu, 2015; Tobias, 2015). In this context, caution is needed when inferring the adaptive capacity of one species from the response of another.

Malaysia is a biodiversity hotspot with high primate diversity but much of its primary forests is being converted into new oil palm plantations, quarries and urban areas (Vijay et al., 2016; Omran \& Schwarz-Herion, 2020). During the past decade, the country has lost $11.3 \%$ of its primary forest and $16.8 \%$ of tree cover (Mongabay, 2021). As reported by the International Union for Conservation of Nature (IUCN, 2020), more than one fourth of Malaysia's mammals are threatened with extinction. Among them are 25 non-human primates (hereafter 'primates'; Roos et al., 2020), one of which is the southern pig-tailed macaque (Macaca nemestrina), a littlestudied, predominantly terrestrial species native to the tropical rainforests of Malaysia, Indonesia and southern Thailand (Ang et al., 2020). The macaques' diet consists primarily of fruits (Caldecott, 1986), indicating their value as seed dispersers (Ruppert et al., 2014) and, consequently, their potential role in forest regeneration (Albert et al., 2014). However, it also suggests that they are frugivorous forest specialists with limited ecological flexibility. The dramatic decline of primary forest habitat in the primates' range, human hunting of macaques for food and the pet trade, and their widespread perception as crop pests have contributed to rapidly decreasing populations during the past few decades (Linkie et al., 2007; Ang et al., 2020). Only recently, Ang et al. (2020) confirmed the macaques' negative population trend and its current status as 'Vulnerable' (IUCN, 2020). Meijaard et al. (2007) reported a generally high sensitivity of this species to logging, yet the macaques' response to human disturbance remains poorly understood (Ang et al., 2020). To date, we lack detailed knowledge on M. nemestrina's distribution, their abundance as well as their ability to cope in anthropogenically impacted habitats. However, these issues are crucial to understand in order to establish effective protection 
119

120

121

122

123

124

125

126

127

128

129

130

131

132

133

134

135

136

137

138

139

140

141

142

143

144

145

146

147

148

149

measures ensuring the long-term survival of this and other threatened wildlife species affected by human activities.

Using available camera trapping data, we provide the first insights into the impact of forest degradation through tree felling on the occupancy of M. nemestrina in Peninsular Malaysia. In order to obtain a broad picture of the effects of human activities on this species, the study comprised two sites that are characterized by different degrees of human disturbance. Firstly, we used a dynamic occupancy modelling approach (MacKenzie et al., 2003) to assess temporal changes in the macaques' distribution as well as factors potentially impacting dynamics in site occupancy in the highly disturbed Pasoh Forest Reserve (PFR), which was affected by partial clear-cutting and selective logging from 2013 to 2017. Secondly, we investigated the macaques' spatial distribution within the Belum-Temengor Forest Complex (BTFC) from 2011 to 2013, focusing on differences between the undisturbed, strictly protected Royal Belum State Park and the selectively logged Temengor Forest Reserve. This direct comparison enables a better understanding of the immediate effects of selective timber extraction on the site occupancy of $M$. nemestrina. Finally, we assessed potential differences in the macaques' age and sex structure in undisturbed as well as selectively logged forests within BTFC. This can inform about vital parameters of population dynamics, particularly breeding success and survival, and therefore be indicative of population health.

Although M. nemestrina readily leaves its natural forest habitat to enter oil palm plantations in search of food (Ruppert et al., 2018; Holzner et al., 2019), it is described as a shy and elusive macaque species that tends to avoid human-dominated areas (Bernstein, 1967; Oi, 1990). Recent studies highlighted the macaques' dependency on primary forest habitat as a safe retreat to sleep and socialize (Ruppert et al., 2014, Holzner et al. 2021), confirming previous doubts on their ability to permanently persist in highly disturbed habitats (Caldecott, 1986). Accordingly, we predicted that forest clearance negatively affects the macaques' ability to occupy a specific habitat, and hence a general decline in site occupancy in PFR during the sampling period. As a predominantly frugivorous species, $M$. nemestrina may also be sensitive to less intensive forms of habitat degradation, such as selective timber harvesting. Thus, we predicted macaques site occupancy to be lower in selectively logged compared to undisturbed forests within BTFC. In line with this, we predicted measures describing the accessibility of a site to humans, such as the distance to the nearest human settlement or the forest edge, to negatively affect macaque site 
150 occupancy. These may serve as a proxy for hunting pressure, which has been suggested to be one 151 of the major risks to wildlife in disturbed habitats (Milner-Gulland \& Bennett, 2003; Tilker er al., 152 2019). In addition, environmental factors may influence macaque site occupancy. Based on 153 previous studies (Yanuar et al., 2009; McCain \& Grytnes, 2010; Ang et al., 2020), we predicted 154 elevation, defining different floristic zones and thus food availability, to be an indicator of the 155 suitability of a site for M. nemestrina. Yanuar et al. (2009) reported that this species is best 156 adapted to lowland and hill dipterocarp forests up to 900 metres above sea level. Importantly, 157 anthropogenic impact on animals' natural habitats may further be associated with demographic 158 changes in wildlife populations (Klass, Van Belle \& Estrada, 2020; Shil, Biswas \& Kumara, 159 2020). Particularly, a proportionally low number of juveniles resulting from low birth rates can 160 be indicative for a declining population (Rudran \& Fernandez-Duque, 2003; Shil, Biswas \& 161 Kumara, 2020). Moreover, skewed adult sex ratios have previously been linked to increased

162 163 164 165 166 167 168 169 170 171

\section{Methods}

173 Study sites

174 Our study was conducted at two different sites in Peninsular Malaysia, which are characterized

mortality within the dispersing sex in animal populations, owing to the risk of migration (Zunino et al., 2007; Klass, Van Belle \& Estrada, 2020). Accordingly, we finally predicted differences in the macaques' age and sex structure between habitats with varying degrees of disturbance. Specifically, we hypothesized the ratio of immature to adult individuals to be lower and the adult sex ratio to be less balanced, potentially with a surplus of females, in disturbed, i.e., selectively logged, forests compared to undisturbed primary forests within the BTFC. As is true for most Cercopithecine primates, female southern pig-tailed macaques are philopatric and form the core of social groups, while male individuals leave their natal group at sexual maturity to breed elsewhere (Cords 2012). by different degrees of human impact. One site is located within the highly disturbed Pasoh Forest Reserve (PFR) in the state of Negeri Sembilan (102'31'0' 'E, 2 $98^{\prime} 0^{\prime}$ ' $N$ ). Large parts of the $140 \mathrm{~km}^{2}$ sized PFR were logged between the 1950s and 1970s, today comprising regenerating lowland forest. Only its $4 \mathrm{~km}^{2}$ core area still consists of virgin primary forest (Fletcher et al., 2012). Also today, PFR is subject to clear-cutting and selective logging. It is

Peer] reviewing PDF | (2021:04:59765:1:1:NEW 26 Sep 2021) 
180 surrounded by oil palm plantations. The second study site is located within the Belum-Temengor

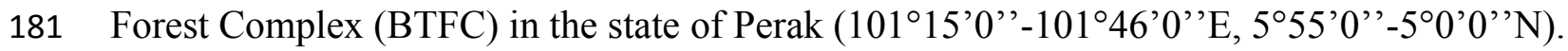

182 BTFC is less intensively impacted by human activities than PFR. With a size of approximately

$1833,000 \mathrm{~km}^{2}$, it forms part of the second-largest contiguous forest complex in Peninsular Malaysia,

184 comprising lowland, hill and upper dipterocarp, as well as montane forest (Rayan \& Linkie,

185 2016). The Gerik-Jeli Highway divides the forest complex into two areas, i.e., the strictly

186 protected Royal Belum State Park (hereafter 'Belum') in the north, and the Temengor Forest

187 Reserve (hereafter 'Temengor'), where selective logging has been ongoing since the 1970s, in

188 the south (Rayan \& Linkie, 2016).

189

190

Camera trap setup

191 This study is based on camera trap data originally collected to assess habitat use of mainland 192 clouded leopards (Neofelis nebulosa) in PFR (Tan et al., 2017) as well as density and habitat use 193 of Malayan tigers (Panthera tigris jacksoni), occupancy of ungulates and interactions between 194 large carnivores in BTFC (Rayan \& Linkie, 2015, 2016, 2020). All necessary permits and 195 support letters from the Perak State Parks Corporation, the Department of Wildlife and National Parks and the Forestry Department of Perak were acquired prior to data collection. Due to the non-invasive nature of observational studies based on camera trapping, no institutional ethical approval was required.

199

Detection data of M. nemestrina from PFR were provided by the Tropical Ecology Assessment and Monitoring Network (TEAM Network 2019, Fletcher \& Campos-Arceiz, 2011). In PFR, camera trapping was conducted from 2013 to 2017. Each camera trap was active for an average of 32 (standard deviation $\mathrm{SD}=5$ ) consecutive days per year. The camera setup covered an area of $120 \mathrm{~km}^{2}$, including a grid of 60 cameras. The spacing between cameras was approximately 1.5 $\mathrm{km}$. Camera images of macaques detected in BTFC were provided by D. Mark Rayan and WWF Malaysia. Here, camera trapping was conducted from 2009 to 2011. Camera traps were active for an average of $87(\mathrm{SD}=32)$ consecutive days between August 2009 and May 2010 in Temengor, and $82(\mathrm{SD}=19)$ consecutive days between August 2010 and April 2011 in Belum. The camera setup covered an area of approximately $400 \mathrm{~km}^{2}$ in each habitat (Rayan \& Linkie, 2015). A grid of 70 cameras was created in Belum and Temengor, respectively, with each grid cell covering $2 \mathrm{~km} \times 2 \mathrm{~km}$. To increase spatial coverage, the cameras were moved within the grid 
211 after three to four months of operation, resulting in 140 distinct camera locations. The sampling

212 blocks within Belum and Temengor were selected to represent the entire forest by taking into

213 account the proportion of different vegetation types (Rayan \& Linkie, 2015).

214 The placement of camera traps (RECONYX and SONY P41) in PFR and BTFC was chosen to

215 ensure an average distance of about $1 \mathrm{~km}$ between traps (Fig. 1). As the approximate home range

216 size of $M$. nemestrina is $1 \mathrm{~km}^{2}$ (Ruppert et al., 2018; Holzner et al., 2019), a macaque group was

217 unlikely to be detected by two different cameras, ensuring spatial independence between sites.

218 Camera traps were active for 24 hours per day and set to take photos at 10 -second intervals. They

219 were fixed to trees at a height of approximately $50 \mathrm{~cm}$ above the ground. Ground trapping (as

220 opposed to placing cameras higher up in the trees) was reasonable for this species, as $M$.

221 nemestrina has previously been described as a predominantly terrestrial primate, spending on

222 average $56 \%$ of its active time on the forest ground (Ruppert et al., 2018). GPS locations of the

223 cameras were recorded using Garmin GPSMAP® 60CSX hand-held GPS units.

224 The rationale behind including data from two different sites, i.e., PFR and BTFC, despite

225 methodological differences was to provide a broader perspective on how distinct forms of human

226 disturbance may differentially affect macaque site occupancy, and thus to increase the analytical

227 power of this study. While PFR represents a highly degraded habitat that is affected by partial

228 clear-cutting, data from BTFC may specifically inform about the potential impact of selective

229 logging. Further, the analysis of PFR was specifically focused on describing dynamics in pig-

230 tailed macaque site occupancy over time, whereas the analysis of BTFC focused on providing

231 thorough insight into spatial differences between undisturbed and selectively logged forests.

232

233

Detection histories

234 Based on presence and absence data obtained from photographic records, we constructed

235 detection histories for each camera site in PFR and BTFC. For repeated sampling occasions, we

236 recorded a ' 1 ' when macaques were detected and a ' 0 ' when no macaques were detected even

237 though a camera trap was active, either because they were truly absent from a particular site or

238 because they were outside the detection range of a camera trap. Referring to previous studies

239 (Tan et al., 2017; Semper-Pascual et al., 2020), we pooled daily detection/non-detection records

240 for each camera site into sampling occasions of seven (PFR) and 14 (BTFC) consecutive days, 
241 respectively, in order to minimize the risk of temporal interdependence among occasions and to

242 increase the overall detection probability. The periods of one and two weeks, respectively, were

243 chosen to maximize the model fit according to the different data collection methods used across

244 sites, as low probabilities of detection can prevent model convergence (Dillon \& Kelly, 2007;

245 Tan et al., 2017). As several camera traps within BTFC intermittently failed to record data for at

246 least two sampling occasions and thus were excluded from analysis, the final datasets of Belum

247 and Temengor included 129 and 125 camera sites, respectively. In PFR, all 60 camera traps were

248 functioning. The total number of sampling occasions per year ranged between two and nine

249 (mean $\pm \mathrm{SD}=5.5 \pm 2.0)$ in PFR and between two and eleven (mean $\pm \mathrm{SD}=7.0 \pm 1.9)$ in $\mathrm{BTFC}$.

250

251 Occupancy modelling

252 Using a maximum likelihood approach, occupancy models account for imperfect detection by

253 linking a state model determining occupancy ( $\psi$, i.e., the probability with which a species occurs

254 at a specific site), with an observation model determining detection probability ( $p$, i.e., the ability

255 to detect a species when it is present) based on repeated samples from the same site (MacKenzie

256 et al., 2002). Variation in probabilities across sampling sites and observation periods can be

257 modelled using site-specific (e.g., habitat variables) and observation-specific (e.g., the sampling

258 effort) covariates.

259 Firstly, to assess temporal changes in the macaques' distribution in the PFR, we fit the dynamic 260 occupancy model described by MacKenzie et al. (2003). This assesses site occupancy dynamics

261 over multiple seasons by estimating, besides detection $(p)$ and first year occupancy $(\psi)$, the

262 probabilities of colonization $(\gamma$, i.e., the probability that a species is present at a previously

263 unoccupied site) and extinction ( $\varepsilon$, i.e., the probability that a species is absent at a previously

264 occupied site, MacKenzie et al., 2003). We included the mean elevation per camera grid cell

265 (range $=94-664 \mathrm{~m}$, mean $\pm \mathrm{SD}=295 \pm 156 \mathrm{~m}$ ) and the shortest distance to the forest edge (range

$266=5-2865 \mathrm{~m}$, mean $\pm \mathrm{SD}=1076 \pm 695 \mathrm{~m}$ ) as potential predictors for first year $\psi$. Both altitude, as

267 well as edge effects, which are likely to affect microclimate and tree communities in areas near

268 the forest border, are known to be important factors in predicting the distribution of wildlife

269 species, including primates (McCain \& Grytnes, 2010; Brodie, Giordano \& Ambu, 2015).

270 Further, a shorter distance of a camera site from the forest edge may facilitate human access and

271 thus increase the hunting pressure (Milner-Gulland \& Bennett, 2003). Additionally, we modelled 
272 variation in $\gamma$ and $\varepsilon$ using a yearly site-specific categorial covariate describing differences in the

273 occurrence and intensity of forest degradation through tree felling between camera sites and

274 sampling years. Based on previous studies reporting a high variation in species' responses

275 depending on the severity of human activity (Gibson et al., 2011; Tobias, 2015), we

276 distinguished between clear-cutting, i.e., land use change resulting in the loss of the entire forest

277 cover in a specific area, selective logging, i.e., the removal of a limited number of economically

278 valuable trees for the timber industry, and no disturbance/tree felling. As previous research

279 highlighted that primate populations may still be critically affected several years after tree felling

280 took place (Shelton, 1985; Rao \& Schaik, 1997), we classified a site as clear-cut or selectively

281 logged if the respective type of forest degradation occurred during the past five years. Finally,

282 we included the survey effort, i.e., the number of days a camera trap was active during a

283 sampling occasion (range $=1-7$, mean $\pm \mathrm{SD}=6.0 \pm 1.8$ days), the sampling month (Jan, Feb,

284 May-Dec) and the sampling year (2013-2017) as predictors for $p$ in order to account for seasonal

285 variation and the effects of abiotic factors on the macaques' activity (Takemoto, 2004; Hanya et

286 al., 2018). Based on the six predictor variables, we constructed the full model and subsequently

287 built candidate models with all possible combinations of predictor sets.

288 Secondly, to assess the macaques' spatial distribution within the BTFC, we fit a single-season

289 occupancy model (MacKenzie et al., 2002). We are confident that our dataset, including

290 sampling periods of a maximum length of five months, meets the closure assumption of

291 occupancy modelling (i.e., that the occupancy status of a site does not change during the

292 sampling, MacKenzie et al., 2002), as previous studies suggested home range areas of $M$.

293 nemestrina to be stable even over several years (Ruppert et al., 2018; Holzner et al., 2019). As

294 above, we included the mean elevation per grid cell (range $=323-1664 \mathrm{~m}$, mean $\pm \mathrm{SD}=737 \pm$

$295302 \mathrm{~m}$ ) as a potential predictor for $\psi$. To account for the effects of habitat degradation on $\psi$, we

296 further modelled the habitat type (undisturbed Belum or selectively logged Temengor), and the

297 mean Normalized Difference Vegetation Index (NDVI, range $=0.45-0.85$, mean $\pm \mathrm{SD}=0.78 \pm$

298 0.05,). The NDVI estimates the density of green on a patch of land by measuring differences

299 between visible and near-infrared reflectance of vegetation cover, thus having frequently been

300 used as a proxy to describe the bio-structural changes in vegetation caused by land clearing and

301 logging (Weier \& Herring, 2000; Rayan \& Linkie, 2015; Hamel et al., 2009). It was computed

302 using ASTER satellite images from 2008 to 2011 with a 15-metre spatial resolution (Rayan \& 
303 Linkie, 2015). Additionally, we included the distance to the nearest human settlement, including 304 indigenous villages and logging camps in the forest (range $=662-20643 \mathrm{~m}$, mean $\pm \mathrm{SD}=8099 \pm$

305

306

307

308

309

310

311

312

313

314

315

316

317

318

319

320

321

322

323

324

325

326

327

328

329

330

331

332

333

$4756 \mathrm{~m}$ ), as this may be indicative of the intensity of human hunting of macaques at a camera site (Milner-Gulland \& Bennett, 2003). Unlike in PFR, we did not expect pronounced edge effects in BTFC, as it comprises huge areas of continuous forest habitat, with the majority of camera traps being located several kilometres from the forest border. The approximate home range area of $M$. nemestrina, on the other hand, is only $1 \mathrm{~km}^{2}$. Finally, to account for variation in $p$, we included the survey effort (range $=1-14$ days, mean $\pm \mathrm{SD}=12.1 \pm 3.6$ days) and the sampling month (Jan-May, Aug-Dec) as observation-specific predictors into the model. As described above, we constructed the full model based on all six predictor variables and then built candidate models with all possible combinations of these predictors.

We fitted the occupancy models for PFR and BTFC, respectively, using the functions colext and осси from the package 'unmarked' (version 1.0.1, Fiske \& Chandler, 2011) in R (version 3.4.4, R Core Team, 2018). To facilitate model interpretation and convergence, we standardized all continuous predictors before model fitting to a mean of zero and a standard deviation of one (Schielzeth, 2010). We checked for collinearity between continuous covariates using Spearman's rank correlation. Covariates were considered independent if their correlation coefficient $\left|r_{\mathrm{s}}\right| \leq 0.7$ (Dormann et al., 2013). This was the case for all covariate pairs included in the same model. We drew inference using multi model inference based on Akaike's information criterion (AIC, Burnham \& Anderson, 2002). Following recommendations of MacKenzie (2006), we first modelled detection, identifying a suitable covariate structure for $p$ while holding $\psi$ and, in the dynamic model of PFR, $\gamma$ and $\varepsilon$ at the most general model including all covariates. Having identified the most parsimonious model structure for $p$, we kept this constant and modelled occupancy, colonization, and extinction, respectively. This two-step approach may be advantageous over maintaining a general model for $p$, as it reduces the number of parameters being estimated (MacKenzie, 2006). We assessed the role of our covariates on $\psi, \gamma$ and $\varepsilon$ by ranking all candidate models according to their AIC corrected for small sample sizes $\left(\mathrm{AIC}_{\mathrm{c}}\right.$, Burnham \& Anderson, 2002). We considered top-ranked models as those with $\Delta \mathrm{AIC}_{\mathrm{c}} \leq 2$ (Burnham \& Anderson, 2002). Model estimates were obtained by averaging over all candidate models using the zero method (Nakagawa \& Hauber, 2011). We tested the goodness of fit of the global models by comparing the observed Chi-square statistics to respective reference

Peer) reviewing PDF | (2021:04:59765:1:1:NEW 26 Sep 2021) 
334 distributions calculated from 1000 parametric bootstraps (MacKenzie \& Bailey, 2004). This

335 indicated no lack of fit for both models (both $\mathrm{P}>0.05$, further details and $\mathrm{R}$ functions used in

336 Supplemental Methods).

337

338 Assessment of the macaques' age and sex structure

339 To gain a deeper insight into the viability of $M$. nemestrina in selectively logged forests, we 340 compared age and sex ratios in the macaque populations in Belum and Temengor, respectively, 341 based on camera trap images. Due to a combination of time constraints for completing analyses, 342 and the fact that images were not immediately accessible from PFR, which would have required 343 time to individually download, organise and review before age and sex classifications could be 344 established, this assessment was restricted to BTFC.

345 Each individual detected was identified as adult male, adult female, subadult, juvenile or infant 346 according to its body size, sexual characteristics (e.g., anogenital swelling and elongated nipples 347 in females or prominent testes in males, Bullock et al., 1972), or individual behaviour (e.g., 348 juveniles ranging in frequent proximity to their mother or infants nipple holding). Individuals 349 that were partly hidden from view and thus could not be clearly assigned to either of these 350 categories were marked as 'unknown'. We then summed the number of independent detections 351 in each age and sex class, separately for each of the two habitats. Following O'Brien et al. (2003) 352 and Kafley et al. (2019), we defined independent detections as (1) consecutive photographs of 353 identifiable different individuals based on their unique characteristics, (2) consecutive 354 photographs of individually unrecognizable macaques of the same age and sex class taken more than 30 minutes apart, or (3) non-consecutive photographs of individuals of the same age and sex class. As described above, spatial independence between camera sites was assumed due to the generally small home range size of approximately $1 \mathrm{~km}^{2}$ of $M$. nemestrina (Ruppert et al., 2018; Holzner et al., 2019). The identification of individuals in images across cameras was not possible in the framework of this study. We assessed differences in the macaques' age and sex structure between Belum and Temengor using a Chi-square test for independence.

\section{$\underline{\text { Results }}$}


363

364

365

366

367

368

369

370

371

372

373

374

375

376

377

378

379

380

381

382

383

384

385

386

387

388

389

390

391

392

Detection of macaques in PFR and BTFC

Within PFR, we detected M. nemestrina during 42.3\% of in total 1636 independent sampling occasions. The naïve occupancy, i.e., the proportion of camera sites with at least one detection (MacKenzie et al., 2006), ranged between 0.80 and 0.93 during the five-year sampling period, with the highest rate recorded in 2013. In the BTFC, macaques were present during $13.3 \%$ of 1774 sampling occasions. The naïve occupancy was 0.53 in the undisturbed forest of Belum and 0.39 in the selectively logged forest of Temengor.

Based on $\mathrm{AIC}_{\mathrm{c}}$, camera trapping effort and the sampling date significantly contributed to explaining the variation in the detection probability of $M$. nemestrina (Table 1). Specifically, detection was positively correlated with the number of trapping days at both study sites, i.e., PFR and BTFC (model estimate \pm standard error $(\mathrm{PFR} / \mathrm{BTFC})=0.51 \pm 0.06 / 0.61 \pm 0.12)$, and varied between sampling year and sampling month, respectively, indicating the presence of seasonal effects (details in Table S2). The mean estimated detection probability across all camera sites was $0.48(\mathrm{SD}=0.15)$ in PFR and $0.23(\mathrm{SD}=0.11)$ in BTFC.

\section{Temporal changes in macaque site occupancy in the highly disturbed PFR}

Using a dynamic occupancy modelling approach, we aimed at predicting temporal changes in macaque site occupancy as well as their potential causes in PFR. The initial occupancy probability of $M$. nemestrina in PFR was estimated to be 0.95 (standard error $(\mathrm{SE})=0.03$ ), when fixing elevation and the distance to the forest edge at their mean values. Macaque site occupancy in subsequent years was found to decrease by 10\% from 0.95 in 2013 to 0.85 in 2017 (Fig. 2).

Further, we assessed the role of environmental and anthropogenic factors in predicting occupancy, colonization and extinction in PFR. Accordingly, only the top-ranked model, including forest degradation (arising from tree felling through clear-cutting or selective logging) as a predictor for extinction, received substantial support $\left(\Delta \mathrm{AIC}_{\mathrm{c}} \leq 2\right.$, Table 2$)$. In line with this, model-averaged coefficients corroborated the effect of forest degradation on the local extinction probability of M. nemestrina in PFR (Table 3). Specifically, we found that the macaques were approximately six times more likely to be absent at a previously occupied camera site in areas affected by clear-cutting compared to undisturbed forest patches (Fig. 3). No significant effect could be found for selective logging, yet large confidence intervals indicate a high variability in 
393 the response of $M$. nemestrina to this less intensive form of habitat degradation, potentially

394 relating to small sample sizes as well as different practices and intensities of selective timber

395 harvesting (Fig. 3). Further, low model-averaged coefficients and 95\% confidence intervals

396 including zero suggest that both elevation and the distance of a camera site to the forest edge did

397 not significantly affect macaque site occupancy in PFR (Table 3).

398

399

Macaques' spatial distribution in undisturbed and selectively logged forests within BTFC

400 To better understand the effects of selective logging on M. nemestrina, we assessed the macaque

401

402

403

404

405

406

407

408

409

410

411

412

413

414

415

416

417

418

419

420

421

422

distribution as well as the covariate structure that best explains variation in occupancy probabilities within BTFC. Unlike in PFR, we found evidence that elevation had a strong effect on site occupancy in BTFC, as indicated by its inclusion in the top-ranked model $\left(\triangle \mathrm{AIC}_{\mathrm{c}} \leq 2\right.$, Table 2). Specifically, occupancy probability was found to significantly decrease with increasing elevation (Table 3, Fig. 4). Further, low model-averaged coefficients and comparatively large 95\% confidence intervals suggest that occupancy did not significantly differ between habitats. Predicted occupancy probabilities in the strictly protected forest of Belum and the selectively logged forest of Temengor were $0.59(\mathrm{SE}=0.08)$ and $0.58(\mathrm{SE}=0.09)$, respectively, when fixing all other covariates at their mean values. Similarly, the NDVI and distance to the closest human settlement had no effect on macaque site occupancy (Table 3).

\section{Macaques' age and sex structure in BTFC}

To explicitly examine the viability of $M$. nemestrina in selectively logged forests, we investigated whether the macaques' age and sex structure differed between intact and partially degraded habitats within BTFC. We detected a total of 614 and 695 individual macaques in Belum and Temengor, respectively, $96 \%$ of which could be unambiguously assigned to an age and sex class. Chi-square test of independence did not reveal significant differences in the age and sex ratio between the undisturbed forest of Belum and the selectively logged forest of Temengor $\left(\chi^{2}=0.45, \mathrm{df}=4, \mathrm{p}=0.98\right)$. In both habitats, approximately $60 \%$ of detected individuals were adults, while $40 \%$ of detections were immatures including subadults, juveniles and infants (Fig. 5).

Peer] reviewing PDF | (2021:04:59765:1:1:NEW 26 Sep 2021) 


\section{Discussion}

424 Globally, increasing human encroachment into natural habitats is a major cause of biodiversity 425 loss (Marques et al., 2019), yet previous studies have highlighted the high variability in species' 426 ability to cope with anthropogenic impact (Brodie, Giordano \& Ambu, 2015). This study

427 provides the first insights into the distribution of $M$. nemestrina across intact and degraded forest 428 habitats in Peninsular Malaysia, focusing on the effects of tree felling on macaque occupancy 429 over time and space. Specifically, clear-cutting significantly increased the probability that $M$. 430 nemestrina became locally extinct at a previously occupied site as compared to a site without 431 tree felling, likely accounting for the considerable decline in site occupancy observed in PFR 432 during the five-year study period from 2013 to 2017 . However, there was no difference in the 433 extinction probability of $M$. nemestrina between selectively logged and undisturbed sites within 434 PFR, which is consistent with our findings from BTFC where occupancy probabilities did not 435 depend on whether a site was located in the strictly protected forest of Belum or the selectively 436 logged forest of Temengor. Importantly, all occupancy measures were obtained while controlling

437 for differences in the detection probability of $M$. nemestrina between the study sites. Finally, 438 there were no differences in the macaques' age and sex structure between Belum and Temengor, 439 suggesting that low to moderate habitat degradation, such as selective logging, is not necessarily 440 linked to declining populations, as would be indicated by an increased ratio of adults to 441 immatures (Rudran \& Fernandez-Duque, 2003; Shil, Biswas \& Kumara, 2020). Rather, this

442 species may be able to maintain viable populations in selectively logged forests. Further, similar 443 sex ratios do not imply negative effects of selective timber harvesting on the survival of 444 dispersing males (Rudran \& Fernandez-Duque, 2003; Zunino et al., 2007; Klass, Van Belle \& 445 Estrada, 2020).

446 As one of the world's leading palm oil producers, Malaysia continues to be affected by 447 deforestation, which has dramatic consequences for many tropical species that rely on primary 448 rainforest (Vijay et al., 2016; Estrada et al., 2017). Our results provide evidence that southern 449 pig-tailed macaques are particularly threatened by intensive forest clearance. Clear-cutting for 450 the purpose of converting natural forest, whether undisturbed or previously selectively logged, 451 into other land use forms, including agricultural land, is likely to dramatically reduce the 452 suitability of a habitat for this species. In degraded forests, wildlife may suffer from habitat 453 fragmentation, reduced availability of natural food sources, and a high human hunting pressure 
454 facilitated by the increased accessibility to the remaining forest patches (Johns, 1985; Tilker et

455 al., 2019). Previous studies emphasized the primates' dependency on preserved natural forests in 456 and around these highly disturbed landscapes to successfully disperse and reproduce (Ancrenaz 457 et al., 2021), as well as to perform the full range of their natural behavioural repertoire (Holzner 458 et al., 2021). The latter includes the formation of strong social relationships, which are critical 459 characteristics of group-living animals owing to their crucial link to individual fitness (Cameron, 460 Setsaas \& Linklater, 2009; Schülke et al., 2010; Ellis et al., 2019) and offspring survival (Silk, 461 Alberts \& Altmann, 2003).

462 In the light of the rising global demand for palm oil, it is inevitable to focus conservation actions 463 on reducing the negative environmental impacts of oil palm monocultures. Recent research has assessed the viability of potential palm oil substitutes, such as sunflower and coconut oil or single cell oil from yeast and microalgae (Parsons et al., 2020). Yet, due to its high-per hectare yield and unique lipid profile, palm oil still outweighs the available alternatives (Parsons et al., 2020). Therefore, the promotion of sustainable practices in the palm oil sector, including the avoidance of further deforestation, the refrainment from the use of chemical fertilizer and pesticides, as well as the establishment of green corridors and buffer zones, is of utmost importance to allow animals to pertain and survive in the forest-plantation matrix, and thus to prevent further loss of wildlife biodiversity.

Unlike clear-cut habitats, less intensively disturbed, selectively logged forests, may indeed sustain viable macaque populations under certain conditions. In this context, elevation in particular appears to be an important factor in predicting whether macaques occur at a given site. This is unsurprising, as elevation defines different floristic zones and thus determines food availability for a variety of species, such as the predominantly frugivorous southern pig-tailed macaque (Saw, 2010). Previous studies have highlighted the impact of elevation on the occurrence and abundance of wildlife. McCain \& Grytnes (2010), for example, found a general trend of declining species richness with increasing elevation across multiple taxa, including small mammals, reptiles, and amphibians. Further, Campera et al. (2020) reported a strong negative correlation between lemur abundance and elevation in the Malagasy rainforests. As predicted, we found macaque site occupancy to decrease with increasing elevation in BTFC. However, PFR lacks this correlation, likely due to low variation between camera sites and generally low altitudes not exceeding $670 \mathrm{~m}$ (range =94-664 m). In BTFC, on the other hand, 
485 altitudes reached up to $1600 \mathrm{~m}($ range $=323-1664 \mathrm{~m})$. Importantly, this difference in altitude

486 between the study sites may explain the general discrepancy between occupancy estimates in

487 PFR and BTFC. While large parts of the BTFC comprise hill and upper dipterocarp forest of mid 488 altitude as well as montane forest (Rayan \& Linkie, 2016), PFR is a lowland rainforest (Fletcher 489 et al., 2012), which was previously reported to be the preferred habitat type of M. nemestrina 490 (Yanuar et al. 2009). This is in line with findings by Goodman \& Ganzhorn (2004) who 491 suggested that the average elevation used by primates in Asia is around $400 \mathrm{~m}$.

492 Another important determinant of the ability of a species to occupy and persist in a habitat is the 493 intensity of human activity, such as the hunting pressure. As demonstrated by Tilker et al. (2019), intensive hunting by humans may be an even more immediate threat to tropical wildlife than moderate habitat degradation. Both the distance to human settlements and the distance to the forest edge were not included in our top-ranked occupancy models, indicating that hunting activities by indigenous tribes, local communities, and logging workers may have been rather low at our study sites. In BTFC, this may be closely linked to low densities of settlements, which entail greater distances averaging $8 \mathrm{~km}$ to camera sites.

500 Earlier studies suggested that species characterized by a more generalist diet, and thus a lower 501 degree of frugivory, may thrive in partially logged habitats (Johns \& Skorupa, 1987; Vetter et al., 502 2011). Some of these were found to even prefer disturbed environments to primary forest. 503 Ungulates, small mammals or omnivorous and granivorous birds, for example, exhibit higher 504 abundances in disturbed or edge-affected habitats compared to undisturbed forests (Lambert, 505 Malcolm \& Zimmerman, 2006; Brodie, Giordano \& Ambu, 2015; Burivalova et al., 2015). 506 Although the main component of M. nemestrina's natural diet are fruits (ca. 75\%, Caldecott, 507 1986), they feed on a wide range of other foods, such as insects, leaves, mushrooms and small 508 mammals (Ang et al., 2020). Southern pig-tailed macaques inhabiting a forest-oil palm matrix at 509 the west coast of Peninsular Malaysia were reported to complement their natural forest diet with 510 cultivated oil palm fruits and plantation rats (Ruppert et al., 2018; Holzner et al., 2019),

511 suggesting that macaques may indeed be able to adapt their diet to changing environmental 512 conditions, as also found for other Malaysian primates (Johns, 1985).

513 Previous findings stressed the importance of accounting for imperfect detection during data 514 collection when studying the occurrence or distribution of wild animals (MacKenzie, 2006). This 
515 proved to be relevant also in our study, as the detection probability, i.e., the probability to detect

516 a species when it is present, varied across study sites. Camera sites in BTFC in particular showed

517 a low probability to detect macaques when present, even after increasing the interval of sampling

518 occasions from seven to 14 days. In PFR, on the other hand, the probability of detection was

519 considerably higher. One crucial factor in explaining this discrepancy in the detection of wildlife

520 may be seasonality. Based on our results, the date of sampling was identified as an important

521 predictor of the detection probability. Prolonged rainfall during the monsoon season may

522 decrease the macaques' overall activity and/or terrestriality (Takemoto, 2004; Hanya et al.,

523 2018), thus resulting in a lower probability of being detected by the camera traps on the ground.

524 While camera trapping in BTFC was performed from August until May, including the rainy

525 season from November until January, in PFR more than 87\% of sampling days took place during

526 the commonly dryer period between May and August, likely resulting in a higher detection

527 probability in PFR compared to BTFC. This effect may be reinforced, as PFR is a relatively

528 small, highly degraded forest surrounded by oil palm plantation, with canopy gaps likely

529 promoting movement of macaques on the ground (Ancrenaz et al., 2014). As pointed out by

530 previous research, small home range areas frequently reported for primate groups ranging in

531 anthropogenic environments, as well as high group densities may also lead to increased detection

532 probabilities (McLennan, Spagnoletti \& Hockings, 2017; Parsons et al., 2017; Neilson et al.,

533 2018), although the available dataset did not allow us to verify this. Furthermore, it is important

534 to note here that, based on our analyses, we can infer macaque occupancy but not necessarily

535 abundance. In order to provide in-depth information on whether or not selective logging affects

536 the long-term viability of M. nemestrina, more detailed studies including larger data sets are

537 needed. However, MacKenzie and Nichols (2004) proposed that occupancy may serve as a

538 surrogate for abundance estimation and some earlier studies found strong associations between

539 occupancy and density in carnivorous species (Clare, Anderson \& MacFarland, 2015; Linden et

540 al., 2017).

541

542 Conclusions

543 There are no population assessments of $M$. nemestrina in its species range, but general estimates

544 are primarily based on assumptions inferred from knowledge available from other primates 
545 occupying the same or similar habitats (Ang et al., 2020). Here, we add to these findings by

546 providing thorough insight into the macaques' ability to persist in human-impacted habitats and

547 quantifying the effect of tree felling activities on the distribution of M. nemestrina. We confirm

548 how population monitoring through camera trapping can contribute to understanding the

549 response of an elusive and threatened Malaysian primate to ecological and anthropogenic factors,

550 and hence to informing conservation efforts. The present study stresses the high sensitivity of $M$.

551 nemestrina to clear-cutting. At the same time, it demonstrates that not only primary forest but

552 also moderately disturbed habitats may play a key role for the protection of this species. Overall,

553 our data indicate that previously selectively logged forests may constitute a valuable habitat for

554 the macaques and therefore should be protected and regenerated instead of opened for more land

555 development. Ultimately, it is imperative to clearly differentiate between these partially

556 degraded, but for the protection of biodiversity, very important forests (Johns, 1985; Lee, Powell

$557 \&$ Lindsell, 2015) and vast areas of monoculture timber plantations. Frequently, the latter are

558 also defined as 'forest' (e.g., Peninsular Malaysia's National Forestry Act of 1984) and thus

559 continue to legally replace selectively logged areas, i.e., potential primate habitats, in many

560 forest reserves after the high-value forest timber had been extracted (Aziz, Laurance \&

561 Clements, 2010). To counteract population declines at accelerated rates, conservation actions

562 need to focus on the maintenance (and if necessary, restoration) of primary and secondary forest

563 habitats (WWF, 2020), including partially degraded forest that can provide valuable habitat for

564 various species, such as M. nemestrina. Specifically, the protection of selectively logged forest

565 against conversion into other land use forms, e.g., monoculture plantations, targeted restoration

566 efforts of degraded habitats, and the reconnection of isolated forests through the establishment of

567 wildlife corridors in fragmented habitats are important conservation measures. This may

568 facilitate natural dispersal between wildlife populations, which is inevitable to ensure the long-

569 term survival of this and other species.

570

571 Acknowledgements

572 We thank the Perak State Parks Corporation, the Department of Wildlife and National Parks and

573 the Forestry Department of Perak for permission to conduct surveys. We are very grateful to the

574 Tropical Ecological Assessment and Monitoring (TEAM) Network and the WWF Malaysia for 
575 sharing camera trap data on southern pig-tailed macaques. A full account of all parties to be

576 credited for the collection of the original data and research funding is given in Rayan and Linkie

$577(2015,2016,2020)$ and Tan et al. (2017). We also thank Monika Sündermann and Brigitte

578 Schlögl for their support in the initial phase of this study, and Ammie Kalan for her advice on the

579 application of occupancy modelling.

580

581

$\underline{\text { Author contributions }}$

582 Idea, N.R.; Conceptualization, A.H., N.R., L.C., H.K. and A.W; Investigation (data provision), 583 D.M.R, J.M. and C.K.W.T.; Formal Analysis, A.H., L.C. and L.K.; Visualization, A.H.; Writing 584 - Original Draft, A.H.; Writing - Review \& Editing, all authors; Funding acquisition, D.M.R., 585 N.R., A.H.

586

587

\section{$\underline{\text { References }}$}

588

589

590

591

592

593

594

595

596

597

598

599

600

601

602

603

604

605

606

607

608

Albert A, McConkey K, Savini T, Huynen M-C. 2014. The value of disturbance-tolerant cercopithecine monkeys as seed dispersers in degraded habitats. Biological Conservation 170:300-310. DOI: 10.1016/j.biocon.2013.12.016.

Alroy J. 2017. Effects of habitat disturbance on tropical forest biodiversity. Proceedings of the National Academy of Sciences of the United States of America 114:6056-6061. DOI: 10.1073/pnas.1611855114.

Ancrenaz M, Oram F, Nardiyono N, Silmi M, Jopony MEM, Voigt M, Seaman DJI, Sherman J, Lackman I, Traeholt C, Wich SA, Santika T, Struebig MJ, Meijaard E. 2021. Importance of small forest fragments in agricultural landscapes for maintaining orangutan metapopulations. Frontiers in Forests and Global Change 4:560944. DOI: 10.3389/ffgc.2021.560944.

Ancrenaz M, Sollmann R, Meijaard E, Hearn AJ, Ross J, Samejima H, Loken B, Cheyne SM, Stark DJ, Gardner PC, Goossens B, Mohamed A, Bohm T, Matsuda I, Nakabayasi M, Lee SK, Bernard H, Brodie J, Wich S, Fredriksson G, Hanya G, Harrison ME, Kanamori T, Kretzschmar P, Macdonald DW, Riger P, Spehar S, Ambu LN, Wilting A. 2014. Coming down from the trees: Is terrestrial activity in Bornean orangutans natural or disturbance driven? Scientific Reports 4:4024. DOI: 10.1038/srep04024.

Ang A, Boonratana R, Choudhury A, Supriatna J. 2020. Macaca nemestrina. The IUCN Red List of Threatened Species 2020. IUCN Red List of Threatened Species:e.T12555A181324867. DOI: 10.2305/IUCN.UK.20203.RLTS.T12555A181324867.en.

Peer] reviewing PDF | (2021:04:59765:1:1:NEW 26 Sep 2021) 
609

610

611

612

613

614

615

616

617

618

619

620

621

622

623

624

625

626

627

628

629

630

631

632

633

634

635

636

637

638

639

640

641

642

643

644

645

646

647

648

Asner GP, Knapp DE, Broadbent EN, Oliveira PJC, Keller M, Silva JN. 2005. Selective logging in the Brazilian Amazon. Science 310:480-482. DOI: 10.1126/science.1118051.

Aziz SA, Laurance WF, Clements R. 2010. Forests reserved for rubber? Frontiers in Ecology and the Environment 8:178-178. DOI: 10.1890/10.WB.014.

Barnes AD, Jochum M, Mumme S, Haneda NF, Farajallah A, Widarto TH, Brose U. 2014. Consequences of tropical land use for multitrophic biodiversity and ecosystem functioning. Nature Communications 5:5351. DOI: 10.1038/ncomms6351.

Bernstein IS. 1967. A field study of the pigtail monkey (Macaca nemestrina). Primates 8:217228.

Bicknell J, Peres CA. 2010. Vertebrate population responses to reduced-impact logging in a neotropical forest. Forest Ecology and Management 259:2267-2275. DOI: 10.1016/j.foreco.2010.02.027.

Brodie JF, Giordano AJ, Ambu L. 2015. Differential responses of large mammals to logging and edge effects. Mammalian Biology 80:7-13. DOI: 10.1016/j.mambio.2014.06.001.

Bullock DW, Paris CA, Goy RW. 1972. Sexual behaviour, swelling of the sex skin and plasma progesterone in the pigtail macaque. Reproduction 31:225-236. DOI: 10.1530/jrf.0.0310225.

Burivalova Z, Lee TM, Giam X, Şekercioğlu ÇH, Wilcove DS, Koh LP. 2015. Avian responses to selective logging shaped by species traits and logging practices. Proceedings of the Royal Society B: Biological Sciences 282:20150164. DOI: 10.1098/rspb.2015.0164.

Burnham KP, Anderson DR. 2002. Model Selection and Multimodel Inference: A Practical Information-Theoretic Approach, Second Edition. New York, NY: Springer.

Caldecott JO. 1986. An Ecological and Behavioural Study of the Pig-Tailed Macaque. Basel: S. Karger.

Cameron EZ, Setsaas TH, Linklater WL. 2009. Social bonds between unrelated females increase reproductive success in feral horses. Proceedings of the National Academy of Sciences 106:13850-13853. DOI: 10.1073/pnas.0900639106.

Campera M, Santini L, Balestri M, Nekaris K a. I, Donati G. 2020. Elevation gradients of lemur abundance emphasise the importance of Madagascar's lowland rainforest for the conservation of endemic taxa. Mammal Review 50:25-37. DOI: 10.1111/mam.12172.

Clare JDJ, Anderson EM, MacFarland DM. 2015. Predicting bobcat abundance at a landscape scale and evaluating occupancy as a density index in central Wisconsin. The Journal of Wildlife Management 79:469-480. DOI: 10.1002/jwmg.844.

Cochrane MA. 2003. Fire science for rainforests. Nature 421:913-919. DOI: 10.1038 /nature 01437.

Cords M. 2012. The behavior, ecology, and social evolution of cercopithecine monkeys. In: Mitani JC, Call J, Kappeler PM, Palombit RA, Silk JB eds. The Evolution of Primate Societies. Chicago, IL: University Of Chicago Press, 91-112.

Danielsen F, Heegaard M. 1995. Impact of logging and plantation development on species diversity: a case study from Sumatra. In: Sandbukt $\varnothing$ ed. Management of Tropical 
649

650

651

652

653

654

655

656

657

658

659

660

661

662

663

664

665

666

667

668

669

670

671

672

673

674

675

676

677

678

679

680

681

682

683

684

685

686

687

Forests: Towards an Integrated Perspective. Oslo: Centre for Development and the Environment, University of Oslo, 73-92.

Darmaraj MR. 2012. Conservation and ecology of tigers in a logged-primary forest mosaic in Peninsular Malaysia. PhD thesis, Durrell Institute of Conservation and Ecology (DICE), University of Kent.

Didham RK, Hammond PM, Lawton JH, Eggleton P, Stork NE. 1998. Beetle species responses to tropical forest fragmentation. Ecological Monographs 68:295-323. DOI: 10.1890/0012-9615(1998)068[0295:BSRTTF]2.0.CO;2.

Dillon AG, Kelly MJ. 2007. Ocelot activity, trap success, and density in Belize: the impact of trap spacing and animal movement on density estimates. Oryx 41:469-477.Dormann CF, Elith J, Bacher S, Buchmann C, Carl G, Carré G, Marquéz JRG, Gruber B, Lafourcade B, Leitão PJ, Münkemüller T, McClean C, Osborne PE, Reineking B, Schröder B, Skidmore AK, Zurell D, Lautenbach S. 2013. Collinearity: a review of methods to deal with it and a simulation study evaluating their performance. Ecography 36:27-46. DOI: 10.1111/j.1600-0587.2012.07348.x.

Ellis S, Snyder-Mackler N, Ruiz-Lambides A, Platt ML, Brent LJN. 2019. Deconstructing sociality: the types of social connections that predict longevity in a group-living primate. Proceedings of the Royal Society B: Biological Sciences 286:20191991. DOI: 10.1098/rspb.2019.1991.

Estoque RC, Ooba M, Avitabile V, Hijioka Y, DasGupta R, Togawa T, Murayama Y. 2019. The future of Southeast Asia's forests. Nature Communications 10:1829. DOI: 10.1038/s41467-019-09646-4.Estrada A, Garber PA, Rylands AB, Roos C, FernandezDuque E, Fiore AD, Nekaris KA-I, Nijman V, Heymann EW, Lambert JE, Rovero F, Barelli C, Setchell JM, Gillespie TR, Mittermeier RA, Arregoitia LV, Guinea M de, Gouveia S, Dobrovolski R, Shanee S, Shanee N, Boyle SA, Fuentes A, MacKinnon KC, Amato KR, Meyer ALS, Wich S, Sussman RW, Pan R, Kone I, Li B. 2017. Impending extinction crisis of the world's primates: Why primates matter. Science Advances 3:e1600946. DOI: 10.1126/sciadv.1600946.

Fiske I, Chandler R. 2011. unmarked: An R package for fitting hierarchical models of wildlife occurrence and abundance. Journal of Statistical Software 43:1-23. DOI: 10.18637/jss.v043.i10.

Fitzherbert EB, Struebig MJ, Morel A, Danielsen F, Brühl CA, Donald PF, Phalan B. 2008. How will oil palm expansion affect biodiversity? Trends in Ecology \& Evolution 23:538-545. DOI: 10.1016/j.tree.2008.06.012.

Fletcher C, Campos-Arceiz A. 2011. Last updated January 2021. Pasoh Forest Reserve. Available at wildlifeinsights.org (accessed July 19, 2020).

Gallery RE. 2014. Ecology of Tropical Rain Forests. In: Monson RK ed. Ecology and the Environment. The Plant Sciences. New York, NY: Springer, 247-272. DOI: 10.1007/978-1-4614-7501-9_4. 
688

689

690

691

692

693

694

695

696

697

698

699

700

701

702

703

704

705

706

707

708

709

710

711

712

713

714

715

716

717

718

719

720

721

722

723

724

725

726

Gibson L, Lee TM, Koh LP, Brook BW, Gardner TA, Barlow J, Peres CA, Bradshaw CJA, Laurance WF, Lovejoy TE, Sodhi NS. 2011. Primary forests are irreplaceable for sustaining tropical biodiversity. Nature 478:378-381. DOI: 10.1038/nature10425.

Hamel S, Garel M, Festa-Bianchet M, Gaillard J-M, Côté SD. 2009. Spring Normalized Difference Vegetation Index (NDVI) predicts annual variation in timing of peak faecal crude protein in mountain ungulates. Journal of Applied Ecology 46:582-589. DOI: 10.1111/j.1365-2664.2009.01643.x.

Hanya G, Otani Y, Hongo S, Honda T, Okamura H, Higo Y. 2018. Activity of wild Japanese macaques in Yakushima revealed by camera trapping: Patterns with respect to season, daily period and rainfall. PLOS ONE 13:e0190631. DOI: 10.1371/journal.pone.0190631.

Holzner A, Balasubramaniam KN, Weiß BM, Ruppert N, Widdig A. 2021. Oil palm cultivation critically affects sociality in a threatened Malaysian primate. Scientific Reports 11:1-16. DOI: $10.1038 / \mathrm{s} 41598-021-89783-3$.

Holzner A, Ruppert N, Swat F, Schmidt M, Weiß BM, Villa G, Mansor A, Mohd Sah SA, Engelhardt A, Kühl H, Widdig A. 2019. Macaques can contribute to greener practices in oil palm plantations when used as biological pest control. Current Biology 29:R1066R1067. DOI: 10.1016/j.cub.2019.09.011.

Ibarra JT, Martin M, Cockle KL, Martin K. 2017. Maintaining ecosystem resilience: functional responses of tree cavity nesters to logging in temperate forests of the Americas. Scientific Reports 7:4467. DOI: 10.1038/s41598-017-04733-2.

IUCN. 2020.The IUCN Red List of Threatened Species. Available at https://www.iucnredlist.org/en (accessed July 19, 2020).

Johns AD. 1985. Selective logging and wildlife conservation in tropical rain-forest: Problems and recommendations. Biological Conservation 31:355-375. DOI: 10.1016/00063207(85)90091-6.

Johns AD, Skorupa JP. 1987. Responses of rain-forest primates to habitat disturbance: A review. International Journal of Primatology 8:157. DOI: 10.1007/BF02735162.

Kafley H, Lamichhane BR, Maharjan R, Thapaliya B, Bhattarai N, Khadka M, Gompper ME. 2019. Estimating prey abundance and distribution from camera trap data using binomial mixture models. European Journal of Wildlife Research 65:77. DOI: 10.1007/s10344019-1308-0.

Klass K, Belle SV, Estrada A. 2020. Demographic population structure of black howler monkeys in fragmented and continuous forest in Chiapas, Mexico: Implications for conservation. American Journal of Primatology 82:e23163. DOI: 10.1002/ajp.23163.

Koh LP, Wilcove DS. 2007. Cashing in palm oil for conservation. Nature 448:993-994. DOI: 10.1038/448993a.

Lee DC, Powell VJ, Lindsell JA. 2015. The conservation value of degraded forests for agile gibbons Hylobates agilis. American Journal of Primatology 77:76-85. DOI: 10.1002/ajp.22312.

Peer) reviewing PDF | (2021:04:59765:1:1:NEW 26 Sep 2021) 
727

728

729

730

731

732

733

734

735

736

737

738

739

740

741

742

743

744

745

746

747

748

749

750

751

752

753

754

755

756

757

758

759

760

761

762

763

764

765

Linden DW, Fuller AK, Royle JA, Hare MP. 2017. Examining the occupancy-density relationship for a low-density carnivore. Journal of Applied Ecology 54:2043-2052. DOI: 10.1111/1365-2664.12883.

Linkie M, Dinata Y, Nofrianto A, Leader-Williams N. 2007. Patterns and perceptions of wildlife crop raiding in and around Kerinci Seblat National Park, Sumatra. Animal Conservation 10:127-135. DOI: 10.1111/j.1469-1795.2006.00083.x.

MacKenzie DI. 2006. Modeling the probability of resource use: The effect of, and dealing with, detecting a species imperfectly. The Journal of Wildlife Management 70:367-374.

MacKenzie DI, Bailey LL. 2004. Assessing the fit of site-occupancy models. Journal of Agricultural, Biological, and Environmental Statistics 9:300-318. DOI: 10.1198/108571104X3361.

MacKenzie DI, Nichols JD. 2004. Occupancy as a surrogate for abundance estimation. Animal Biodiversity and Conservation 27:461-467.

MacKenzie DI, Nichols JD, Hines JE, Knutson MG, Franklin AB. 2003. Estimating site occupancy, colonization, and local extinction when a species is detected imperfectly. Ecology 84:2200-2207. DOI: 10.1890/02-3090.

MacKenzie DI, Nichols JD, Lachman GB, Droege S, Royle JA, Langtimm CA. 2002. Estimating site occupancy rates when detection probabilities are less than one. Ecology 83:22482255. DOI: 10.1890/0012-9658(2002)083[2248:ESORWD]2.0.CO;2.

MacKenzie DI, Nichols JD, Royle JA, Pollock K, Bailey LL, Hines J. 2006. Occupancy Estimation and Modeling: Inferring Patterns and Dynamics of Species Occurrence. Burlington, MA: Elsevier Academic Press.

Marques A, Martins IS, Kastner T, Plutzar C, Theurl MC, Eisenmenger N, Huijbregts MAJ, Wood R, Stadler K, Bruckner M, Canelas J, Hilbers JP, Tukker A, Erb K, Pereira HM. 2019. Increasing impacts of land use on biodiversity and carbon sequestration driven by population and economic growth. Nature Ecology \& Evolution 3:628-637. DOI: 10.1038/s41559-019-0824-3.

McCain CM, Grytnes J-A. 2010. Elevational gradients in species richness. In: eLS ed. DOI: 10.1002/9780470015902.a0022548.

McLennan MR, Spagnoletti N, Hockings KJ. 2017. The implications of primate behavioral flexibility for sustainable human-primate coexistence in anthropogenic habitats. International Journal of Primatology 38:105-121. DOI: 10.1007/s10764-017-9962-0.

Meijaard E, Sheil D, Marshall AJ, Nasi R. 2007. Phylogenetic age is positively correlated with sensitivity to timber harvest in Bornean mammals. Biotropica 40:76-85. DOI: 10.1111/j.1744-7429.2007.00340.x.

Milner-Gulland EJ, Bennett EL. 2003. Wild meat: the bigger picture. Trends in Ecology \& Evolution 18:351-357. DOI: 10.1016/S0169-5347(03)00123-X.

Mongabay. 2021.Deforestation statistics for Malaysia. Available at rainforests.mongabay.com (accessed February 15, 2021).

Peer] reviewing PDF | (2021:04:59765:1:1:NEW 26 Sep 2021) 
766

767

768

769

770

771

772

773

774

775

776

777

778

779

780

781

782

783

784

785

786

787

788

789

790

791

792

793

794

795

796

797

798

799

800

801

802

803

Myers N, Mittermeier RA, Mittermeier CG, da Fonseca GAB, Kent J. 2000. Biodiversity hotspots for conservation priorities. Nature 403:853-858. DOI: 10.1038/35002501.

Nakagawa S, Hauber ME. 2011. Great challenges with few subjects: Statistical strategies for neuroscientists. Neuroscience \& Biobehavioral Reviews 35:462-473. DOI: 10.1016/j.neubiorev.2010.06.003.

Neilson EW, Avgar T, Burton AC, Broadley K, Boutin S. 2018. Animal movement affects interpretation of occupancy models from camera-trap surveys of unmarked animals. Ecosphere 9:e02092. DOI: 10.1002/ecs2.2092.

O'Brien TG, Kinnaird MF, Wibisono HT. 2003. Crouching tigers, hidden prey: Sumatran tiger and prey populations in a tropical forest landscape. Animal Conservation 6:131-139. DOI: $10.1017 / \mathrm{S} 1367943003003172$.

Oi T. 1990. Population organization of wild pig-tailed macaques (Macaca nemestrina nemestrina) in West Sumatra. Primates 31:15-31. DOI: 10.1007/BF02381027.

Omran A, Schwarz-Herion O. 2020. Deforestation in Malaysia: The current practice and the way forward. In: Omran A, Schwarz-Herion O eds. Sustaining our Environment for Better Future: Challenges and Opportunities. Singapore: Springer, 175-193. DOI: 10.1007/978-981-13-7158-5_11.

Parsons AW, Forrester T, McShea WJ, Baker-Whatton MC, Millspaugh JJ, Kays R. 2017. Do occupancy or detection rates from camera traps reflect deer density? Journal of Mammalogy 98:1547-1557. DOI: 10.1093/jmammal/gyx128.

R Core Team. 2018. R: A language and environment for statistical computing. Vienna, Austria: R Foundation for Statistical Computing. Available at https://www.R-project.org (accessed 24 February 2021).

Rao M, Schaik C. 1997. The behavioral ecology of Sumatran orangutans in logged and unlogged forest. Tropical Biodiversity 4:173-185.

Rayan DM, Linkie M. 2015. Conserving tigers in Malaysia: A science-driven approach for eliciting conservation policy change. Biological Conservation 184:18-26. DOI: 10.1016/j.biocon.2014.12.024.

Rayan DM, Linkie M. 2016. Managing conservation flagship species in competition: Tiger, leopard and dhole in Malaysia. Biological Conservation 204:360-366. DOI: 10.1016/j.biocon.2016.11.009.

Rayan DM, Linkie M. 2020. Managing threatened ungulates in logged-primary forest mosaics in Malaysia. PLOS ONE 15:e243932. DOI: 10.1371/journal.pone.0243932.

Robinson JG, Redford KH, Bennett EL. 1999. Wildlife harvest in logged tropical forests. Science 284:595-596. DOI: 10.1126/science.284.5414.595.

Roos C, Boonratana R, Supriatna J, Fellowes JR, Groves CP, Nash SD, Rylands AB, Mittermeier RA. 2014. An updated taxonomy and conservation status review of Asian primates. Asian Primates Journal 4:2-38.

Peer] reviewing PDF | (2021:04:59765:1:1:NEW 26 Sep 2021) 
804

805

806

807

808

809

810

811

812

813

814

815

816

817

818

819

820

821

822

823

824

825

826

827

828

829

830

831

832

833

834

835

836

837

838

839

840

841

842

843

Rosa IMD, Smith MJ, Wearn OR, Purves D, Ewers RM. 2016. The environmental legacy of modern tropical deforestation. Current Biology 26:2161-2166. DOI: 10.1016/j.cub.2016.06.013.

Rudran R, Fernandez-Duque E. 2003. Demographic changes over thirty years in a red howler population in Venezuela. International Journal of Primatology 24:925-947. DOI: 10.1023/A:1026241625910.

Ruppert N, Holzner A, See KW, Gisbrecht A, Beck A. 2018. Activity budgets and habitat use of wild southern pig-tailed macaques (Macaca nemestrina) in oil palm plantation and forest. International Journal of Primatology 39:237-251. DOI: 10.1007/s10764-018-0032-z.

Saw LG. 2010. Vegetation of Peninsular Malaysia. In: Kiew R, Chung RCK, Saw LG, Soepadmo E, Boyce PC eds. Flora of Peninsular Malaysia. Series II: Seed Plants. Kepong: Forest Research Institute Malaysia, 21-45. DOI: 10.13140/RG.2.1.2072.8486.

Schielzeth H. 2010. Simple means to improve the interpretability of regression coefficients. Methods in Ecology and Evolution 1:103-113. DOI: 10.1111/j.2041-210X.2010.00012.x.

Schülke O, Bhagavatula J, Vigilant L, Ostner J. 2010. Social bonds enhance reproductive success in male macaques. Current Biology 20:2207-2210. DOI: 10.1016/j.cub.2010.10.058.

Semper-Pascual A, Decarre J, Baumann M, Camino M, Di Blanco Y, Gómez-Valencia B, Kuemmerle T. 2020. Using occupancy models to assess the direct and indirect impacts of agricultural expansion on species' populations. Biodiversity and Conservation 29:36693688. DOI: 10.1007/s10531-020-02042-1.

Shelton N. 1985. Logging versus the natural habitat in the survival of tropical forests. Ambio 14:39-41.

Shil J, Biswas J, Kumara HN. 2020. Influence of habitat conditions on group size, social organization, and birth pattern of golden langur (Trachypithecus geei). Primates 61:797806. DOI: 10.1007/s10329-020-00829-y.

Silk JB, Alberts SC, Altmann J. 2003. Social bonds of female baboons enhance infant survival. Science 302:1231-1234. DOI: 10.1126/science.1088580.

Sodhi NS, Posa MRC, Lee TM, Bickford D, Koh LP, Brook BW. 2010. The state and conservation of Southeast Asian biodiversity. Biodiversity and Conservation 19:317-328. DOI: $10.1007 / \mathrm{s} 10531-009-9607-5$.

Takemoto H. 2004. Seasonal change in terrestriality of chimpanzees in relation to microclimate in the tropical forest. American Journal of Physical Anthropology 124:81-92. DOI: 10.1002/ajpa.10342.

Tan CKW, Rocha DG, Clements GR, Brenes-Mora E, Hedges L, Kawanishi K, Mohamad SW, Mark Rayan D, Bolongon G, Moore J, Wadey J, Campos-Arceiz A, Macdonald DW. 2017. Habitat use and predicted range for the mainland clouded leopard Neofelis nebulosa in Peninsular Malaysia. Biological Conservation 206:65-74. DOI: 10.1016/j.biocon.2016.12.012.

Tilker A, Abrams JF, Mohamed A, Nguyen A, Wong ST, Sollmann R, Niedballa J, Bhagwat T, Gray TNE, Rawson BM, Guegan F, Kissing J, Wegmann M, Wilting A. 2019. Habitat 
844

845

846

847

848

849

850

851

852

853

854

855

856

857

858

859

860

861

862

863

864 degradation and indiscriminate hunting differentially impact faunal communities in the Southeast Asian tropical biodiversity hotspot. Communications Biology 2:1-11. DOI: 10.1038/s42003-019-0640-y.

Tobias JA. 2015. Hidden impacts of logging. Nature 523:163-164. DOI: 10.1038/523163a.

Vetter D, Hansbauer MM, Végvári Z, Storch I. 2011. Predictors of forest fragmentation sensitivity in Neotropical vertebrates: a quantitative review. Ecography 34:1-8. DOI: 10.HH/j.1600-0587.2010.06453.x.

Vijay V, Pimm SL, Jenkins CN, Smith SJ. 2016. The impacts of oil palm on recent deforestation and biodiversity loss. PLOS ONE 11:e0159668. DOI: 10.1371/journal.pone.0159668.

Weier J, Herring D. 2000. Measuring Vegetation (NDVI \& EVI): Feature Articles. Available at https://earthobservatory.nasa.gov/features/MeasuringVegetation (accessed February 24, 2021).

WWF. 2020. Living Planet Report 2020 - Bending the Curve of Biodiversity Loss. Almond REA, Grooten M, Petersen T eds. Gland, Switzerland: WWF.

Yanuar A, Chivers DJ, Sugardjito J, Martyr DJ, Holden JT. 2009. The population distribution of pig-tailed macaque (Macaca nemestrina) and long-tailed macaque (Macaca fascicularis) in West Central Sumatra, Indonesia. Asian Primates Journal 1:2-11.

Zunino GE, Kowalewski MM, Oklander LI, González V. 2007. Habitat fragmentation and population size of the black and gold howler monkey (Alouatta caraya) in a semideciduous forest in Northern Argentina. American Journal of Primatology 69:966975. DOI: 10.1002/ajp.20389. 


\section{Figure 1}

Study sites in Peninsular Malaysia.

The maps indicate the camera trap distribution in the Belum-Temengor Forest Complex (left) and Pasoh Forest Reserve (right). Adapted from Darmaraj (2012). 


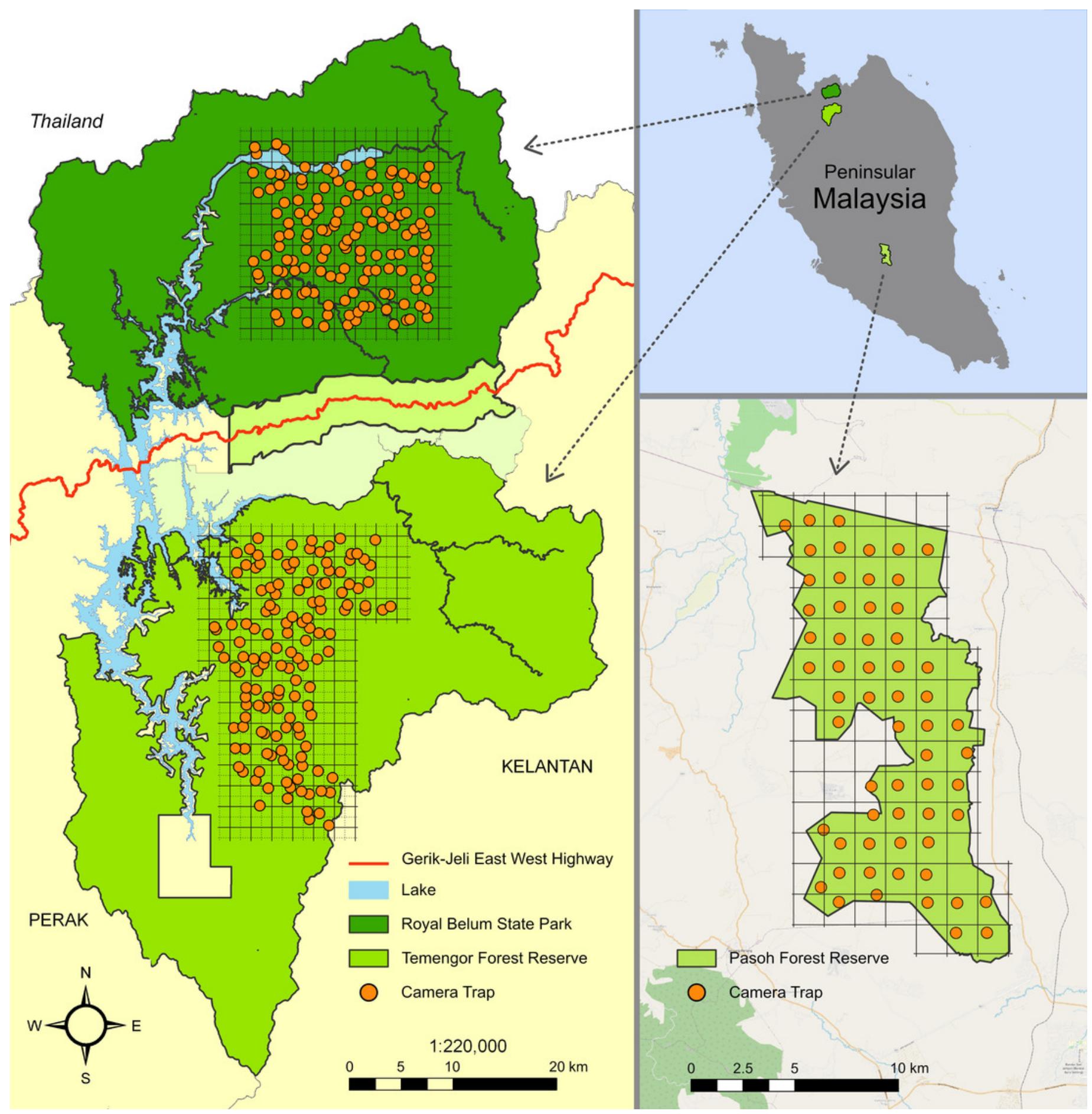


Figure 2

Dynamics in Macaca nemestrina occupancy in the Pasoh Forest Reserve from 2013 to 2017.

Shown are site occupancy estimates, i.e., the predicted proportion of sampled sites that are occupied, and their standard errors $(\mathrm{N}=60)$. The bars indicate the cumulative proportion of sites at which clear-cutting occurred.

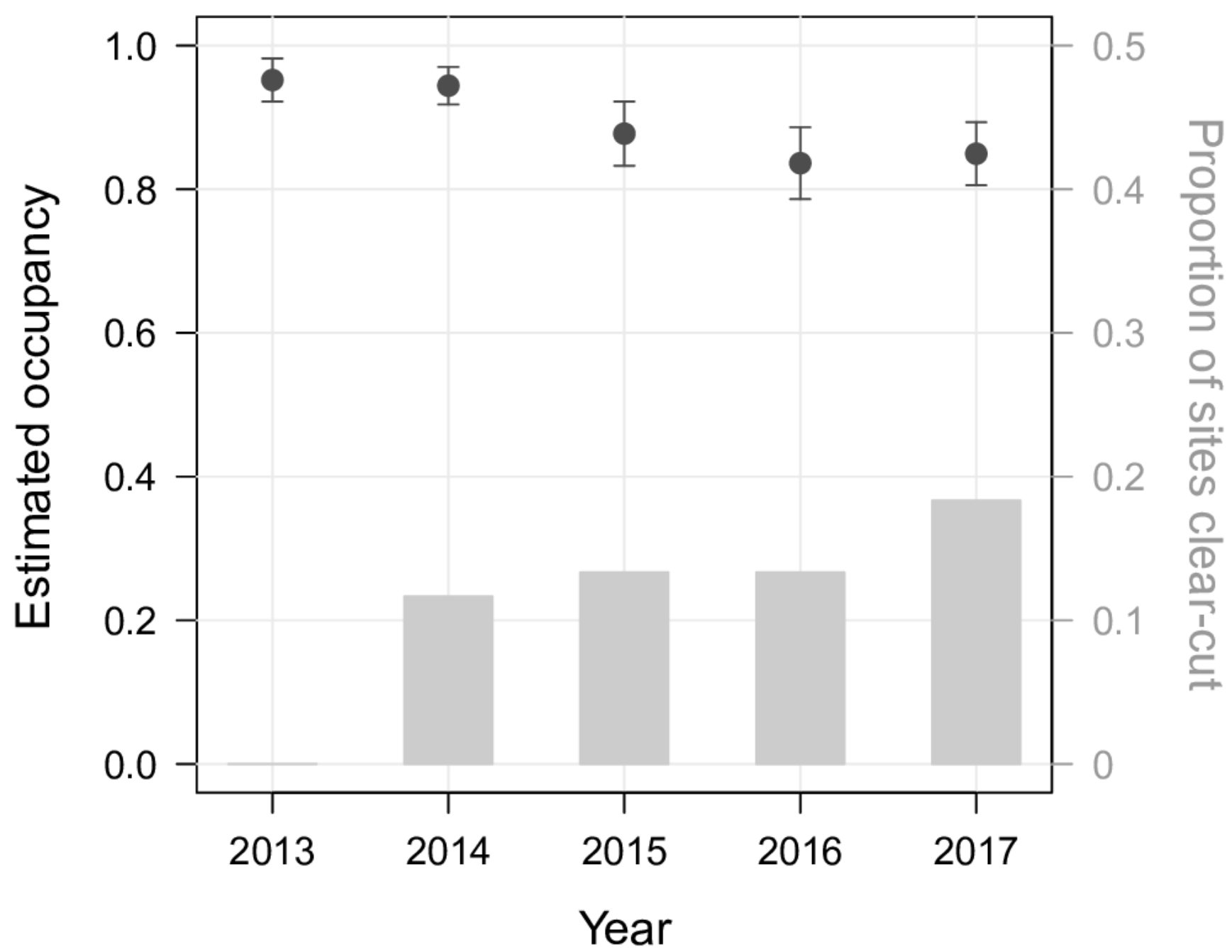


Figure 3

Effect of forest degradation on the local extinction probability of Macaca nemestrina in the Pasoh Forest Reserve.

The filled circles show the fitted model and the whiskers its 95\% confidence interval, conditional on all other predictors being fixed at their mean values. Clear-cutting occurred at a total of 11 sites during the study period, while 5 sites were selectively logged and 44 sites remained undisturbed $(\mathrm{N}=60)$.

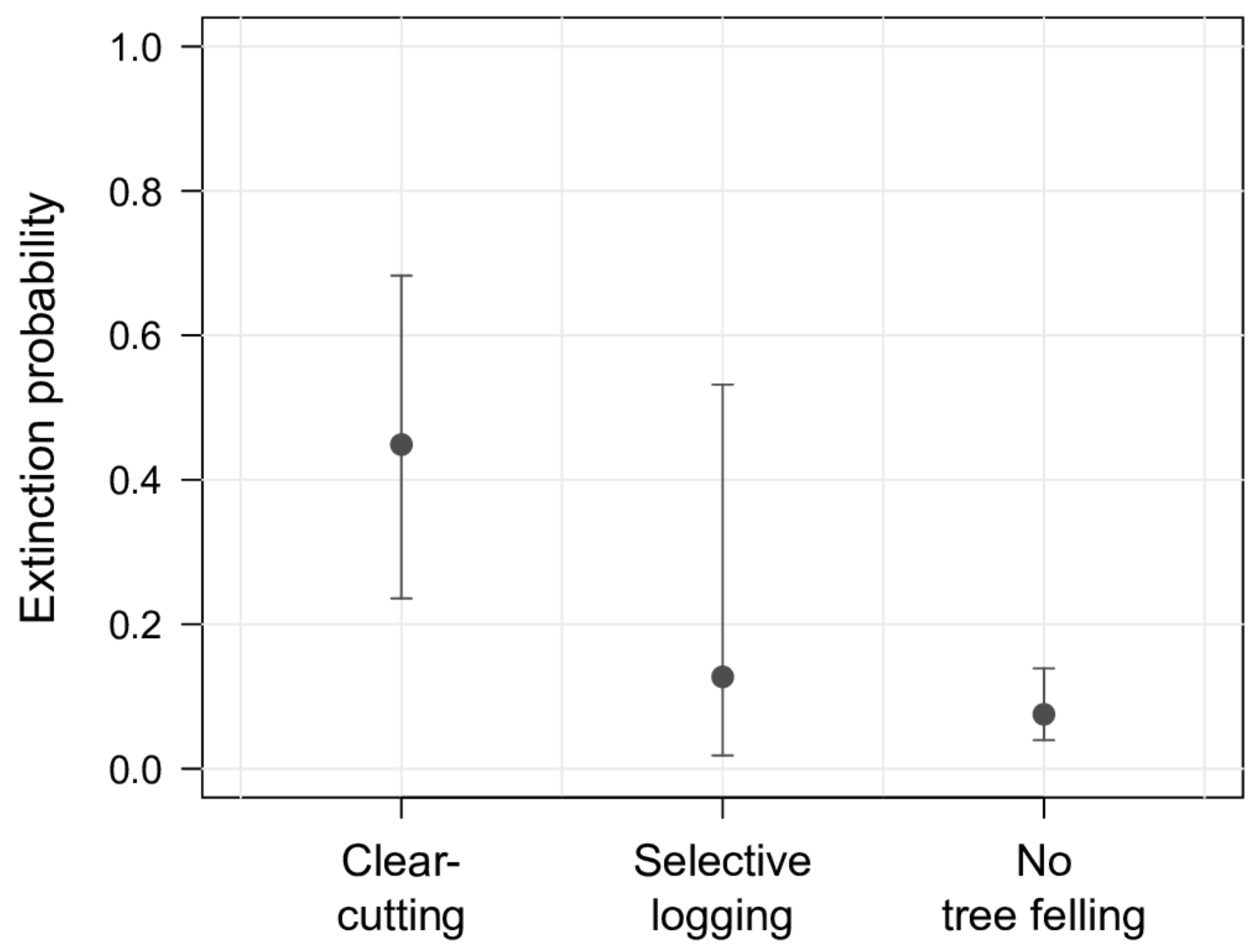


Figure 4

Effect of elevation on site occupancy of Macaca nemestrina in the Belum-Temengor Forest Complex.

The solid line shows the fitted model and the shaded areas its $95 \%$ confidence interval, conditional on all other predictors being fixed at their mean values $(N=254)$. The dashed lines indicate the mean elevation at the two study sites, i.e., the Belum-Temengor Forest Complex (BTFC) and Pasoh Forest Reserve (PFR).

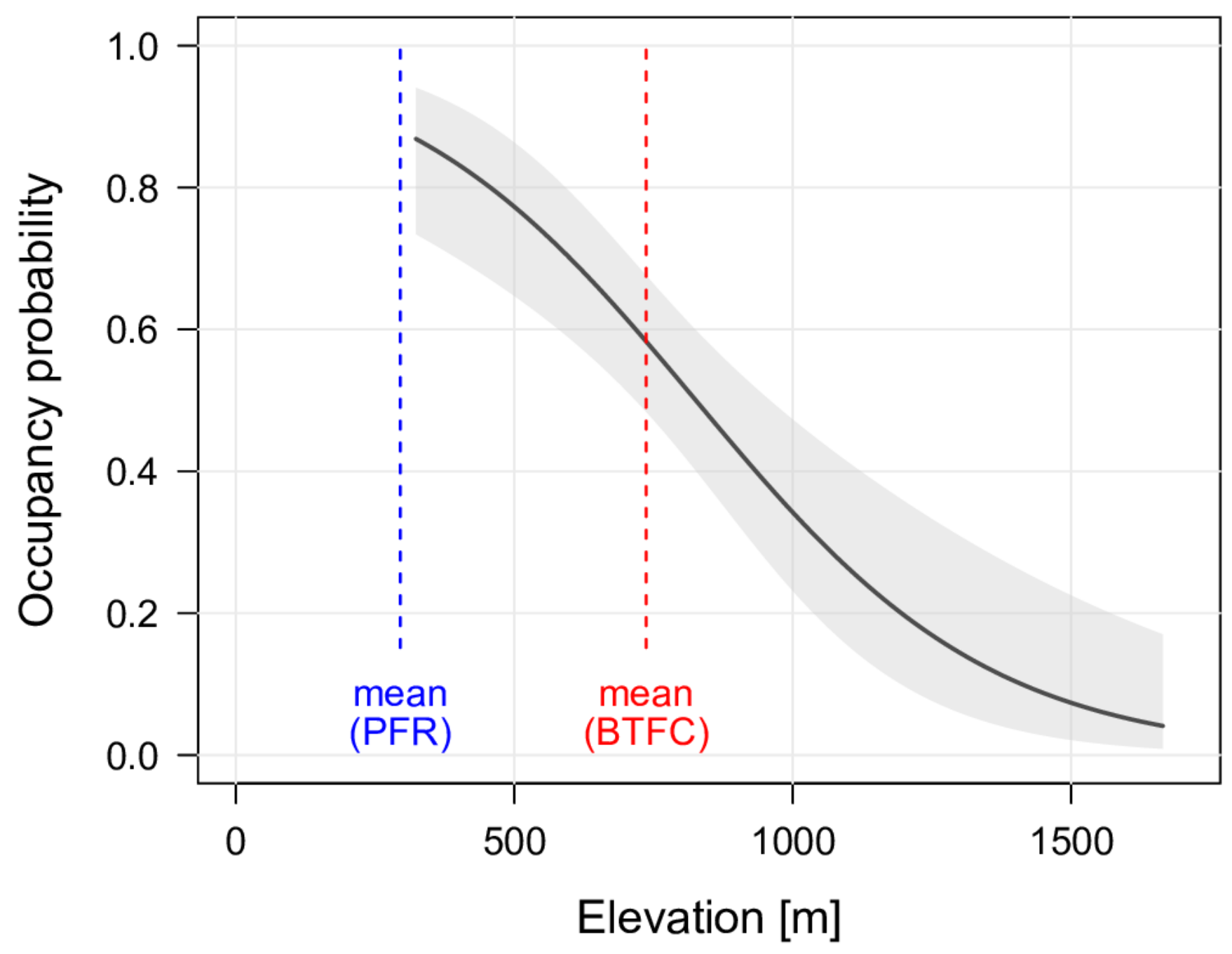




\section{Figure 5}

Age-sex structure of Macaca nemestrina in the Belum-Temengor Forest Complex.

The pie charts indicate the proportion of independent detections of each age-sex category, separately for the Royal Belum State Park (Belum, $N=594$ ) and Temengor Forest Reserve (Temengor, $\mathrm{N}=663$ ).

Royal Belum State Park

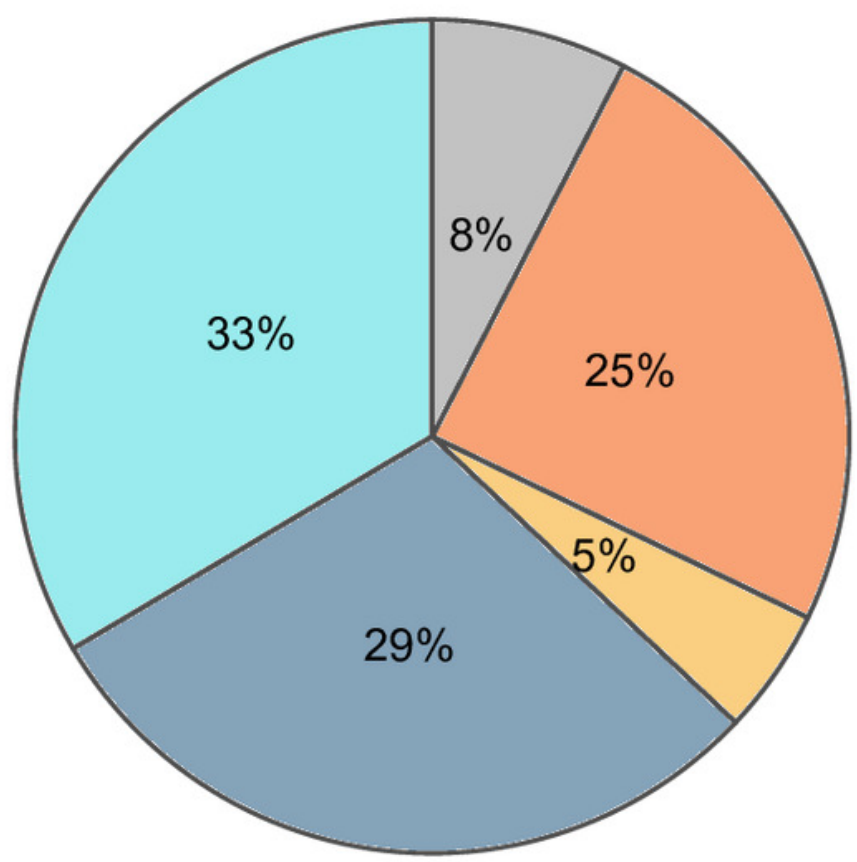

Adult female

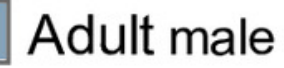

Temengor Forest Reserve

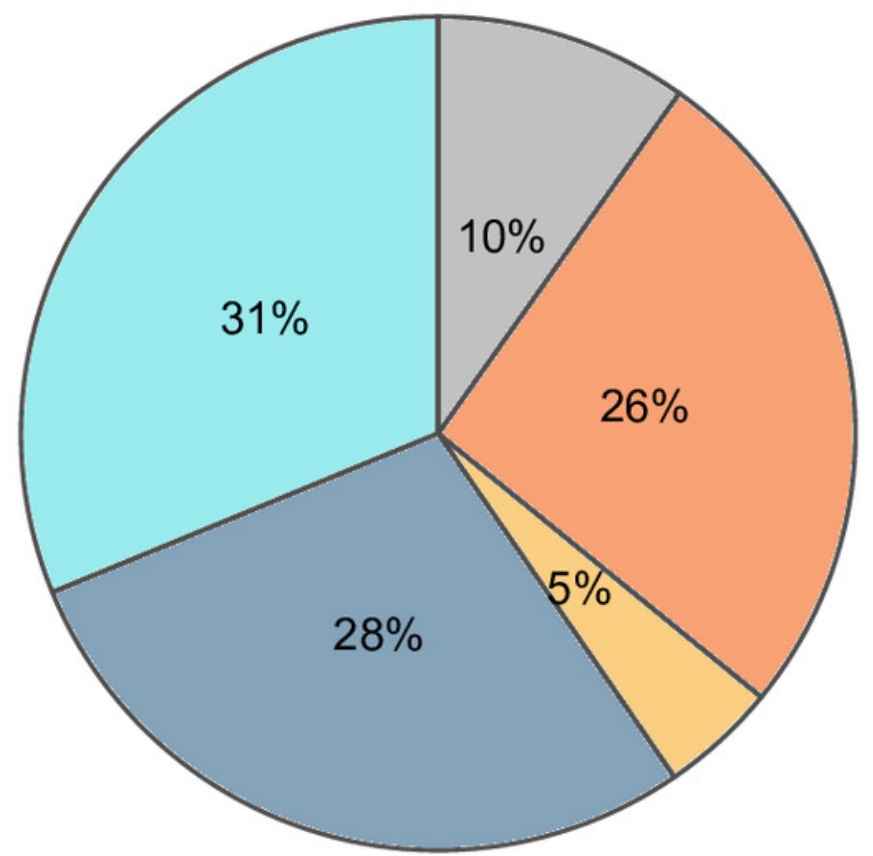

Subadult 


\section{Table $\mathbf{1}$ (on next page)}

Top-ranked Macaca nemestrina detection models $\left(\Delta \mathrm{AIC}_{\mathrm{c}} \leq 2\right)$ for Pasoh Forest Reserve (PFR) and Belum-Temengor Forest Complex (BTFC) with global occupancy models.

Shown are Akaike's Information Criterion corrected for small samples (AIC $C_{c}$, differences in $\mathrm{AIC}_{c}$ between each model and the respective best model $(\Delta \mathrm{AIC})$, the probability of each model to the best model, i.e., the Akaike weights (WAIC), and the number of parameters ( $\mathrm{K}$, details on model selection and model averaged estimates for all covariates in Tables S1 and S2). 


\begin{tabular}{llcccc} 
Site & Top-ranked models & AIC $_{\mathbf{c}}$ & $\mathbf{A A I C}_{\mathbf{c}}$ & wAIC & $\mathbf{K}$ \\
\hline PFR & $p$ (effort + sampling year ) & 2069.5 & 0 & 1 & 15 \\
\hline BTFC & $p$ (effort + sampling month) & 1238.6 & 0 & 0.995 & 16 \\
\hline
\end{tabular}

1 


\section{Table 2 (on next page)}

Top-ranked Macaca nemestrina occupancy models $\left(\triangle \mathrm{AIC}_{\mathrm{c}} \leq 2\right)$ for Pasoh Forest Reserve (PFR) and Belum-Temengor Forest Complex (BTFC) with best respective detection models.

Shown are Akaike's Information Criterion corrected for small samples (AIC $C_{c}$, differences in $\mathrm{AIC}_{\mathrm{c}}$ between each model and the respective best model $\left(\Delta \mathrm{AI} \mathrm{C}_{\mathrm{c}}\right)$, the probability of each model to the best model, i.e., the Akaike weights (WAIC), and the number of parameters ( $\mathrm{K}$, details on model selection in Table S3). 


\begin{tabular}{llcccc} 
Site & Top-ranked models & AIC $_{\mathbf{c}}$ & $\mathbf{A A I C}_{\mathbf{c}}$ & wAIC & $\mathbf{K}$ \\
\hline PFR & $\psi(.) \gamma(.) \varepsilon$ (forest degradation) & 2056.4 & 0 & 0.633 & 11 \\
\hline BTFR & $\psi$ (elevation) & 1232.1 & 0 & 0.415 & 13 \\
\hline
\end{tabular}

1 


\section{Table 3 (on next page)}

Effect of covariates on Macaca nemestrina occupancy, colonization and extinction in the Pasoh Forest Reserve (PFR) and Belum-Temengor Forest Complex (BTFC).

Shown are model averaged estimates (zero method), standard errors (SE) and lower and upper $95 \%$ confidence intervals $(\mathrm{Cl})$. Predictors included into the respective top models $\left(\triangle \mathrm{AIC}_{\mathrm{c}} \leq 2\right)$ are indicated in bold. 


\begin{tabular}{|c|c|c|c|c|c|c|}
\hline Site & Parameter & Covariate & Estimate & SE & lower $\mathrm{Cl}$ & upper $\mathrm{Cl}$ \\
\hline \multirow[t]{6}{*}{ PFR } & Occupancy $\psi$ & distance to edge ${ }^{a}$ & -0.03 & 0.29 & -1.47 & 1.14 \\
\hline & & elevation ${ }^{\mathrm{a}}$ & -0.04 & 0.29 & -1.51 & 1.12 \\
\hline & Colonization $\gamma$ & forest degradation (no vs. clear cut) ${ }^{b}$ & 0.02 & 0.33 & -2.58 & 3.58 \\
\hline & & forest degradation (no vs. selective) ${ }^{b}$ & -0.01 & 0.34 & -3.52 & 2.81 \\
\hline & Extinction $\varepsilon$ & forest degradation (no vs. clear cut) ${ }^{b}$ & 2.25 & 0.69 & 1.13 & 3.48 \\
\hline & & forest degradation (no vs. selective) ${ }^{b}$ & 0.60 & 1.06 & -1.47 & 2.70 \\
\hline \multirow[t]{4}{*}{ BTFC } & Occupancy $\psi$ & habitat (Belum $=0$, Temengor $=1$ ) & -0.001 & 0.23 & -0.90 & 0.90 \\
\hline & & $N D V I^{a}$ & 0.02 & 0.10 & -0.28 & 0.45 \\
\hline & & distance to settlement ${ }^{a}$ & -0.01 & 0.11 & -0.46 & 0.35 \\
\hline & & elevation $^{\mathrm{a}}$ & -1.17 & 0.23 & -1.62 & -0.73 \\
\hline
\end{tabular}

1 a $\mathrm{z}$-transformed to mean $=0$ and SD $=1$ prior to model fitting; original means \pm SDs were: distance to edge: $1076 \pm 695 \mathrm{~m}$, elevation $(P F R): 295 \pm$ $2156 \mathrm{~m}, \mathrm{NDVI}: 0.78 \pm 0.05$, distance to settlement: $8099 \pm 4756 \mathrm{~m}$, elevation (BTFC): $737 \pm 302 \mathrm{~m}$.

3 beference level is 'no tree felling'. 